\title{
ENERGY EXCHANGE BETWEEN HARMONICS IN SWITCHES OF ALTERNATING VOLTAGE REGULATOR AT HIGH-FREQUENCY PULSE-WIDTH MODULATION. II
}

\author{
(Presented by E. Lippmaa)
}

\section{Introduction}

In the first part of this paper $\left.{ }^{1}\right]$ frequency-power relationships have been analyzed for an ideal alternating voltage switching regulator operating in the mode of high-frequency pulse-width modulation in the case of distortion harmonics being suppressed in the load current (mode I). The object of this part of the paper is to derive and analyze the same relationships for the case of distortion harmonics being present in the load current (mode II).

\section{Circuit equations}

The circuit of the alternating voltage regulator is shown in Fig. 1. As in the first part of the paper, it is assumed that the circuit is fed with sinusoidal voltage $u=U_{m} \sin \omega t$ and the switches I and II are ideal. The modulation angular frequency $\Omega=k \omega$, where $k>2$.

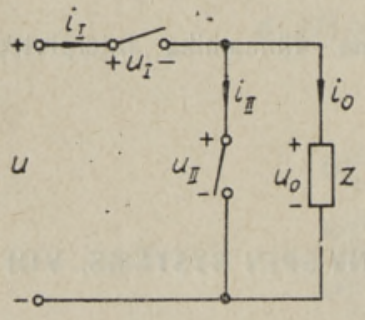

Fig. 1.

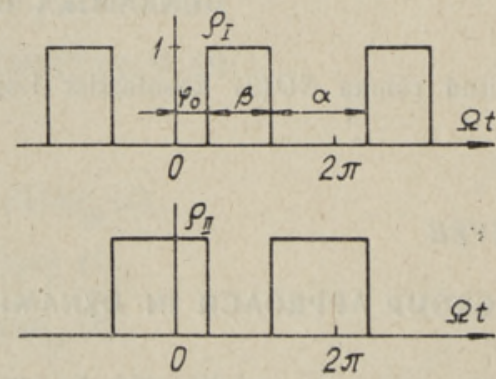

Fig. 2.

The existence functions of the switches are shown in Fig. 2 and can be described by

$$
\begin{aligned}
& \varrho \mathrm{I}=(1-\alpha / 2 \pi)-\sum_{n=1}^{\infty}[2 \sin (n \alpha / 2) \cos (n k \omega t+n \alpha / 2)] / \pi n, \\
& \text { QII }=1-\mathrm{QI} .
\end{aligned}
$$


These equations permit instantaneous voltages and currents of the switches to be expressed as

$$
u_{\mathrm{I}}=u_{\mathrm{II}}, i_{\mathrm{I}}=i_{0} \varrho_{\mathrm{I}}, u_{\mathrm{II}}=u_{\varrho_{\mathrm{I}}}, i_{\mathrm{II}}=-i_{0} \varrho_{\mathrm{II}},
$$

where $i_{0}$ denotes instantaneous output current which, according to representation of currents of the switches used in [ $\left.{ }^{1}\right]$, can be written in the form $\left[{ }^{2}\right]$

$$
\begin{gathered}
i_{0}=i_{0(\omega)}+\sum_{n=1}^{\infty} i_{0 n}=I_{m}(1-\alpha / 2 \pi) \sin (\omega t-\varphi)- \\
-I_{m} \sum_{n=1}^{\infty} \frac{\sin (n \alpha / 2)}{n \pi}\left[\frac{\sin [(n k+1) \omega t+n \alpha / 2-\varphi(n k+1)]}{\left[\cos ^{2} \varphi+(n k+1)^{2} \sin ^{2} \varphi\right]^{1 / 2}}+\right. \\
\left.+\frac{\sin [(n k-1) \omega t+n \alpha / 2-\varphi(n k-1)]}{\left[\cos ^{2} \varphi+(n k-1)^{2} \sin ^{2} \varphi\right]^{1 / 2}}\right],
\end{gathered}
$$

where $\varphi$ is the phase difference between the supply voltage and the fundamental harmonic of the output current; $\varphi_{q}$ (in (4) $q=(n k+1)$, $(n k-1))$ is the phase difference between $q$-th harmonics of the output voltage and current given by $\left[{ }^{2}\right]$

$$
\varphi_{q}=\arccos \left(\cos \varphi /\left(\cos ^{2} \varphi+q^{2} \sin ^{2} \varphi\right)^{1 / 2}\right) .
$$

Instantaneous output voltage $u_{0}$ has the form [ $\left.{ }^{1}\right]$

$$
\begin{gathered}
u_{0}=u_{\mathrm{II}}=u_{0(\omega)}+\sum_{n=1}^{\infty} u_{0 n}=U_{m}(1-\alpha / 2 \pi) \sin \omega t- \\
-U_{m} \sum_{n=1}^{\infty} \sin (n \alpha / 2)[\sin ((n k+1) \omega t+n \alpha / 2)- \\
-\sin ((n k-1) \omega t+n \alpha / 2)] / n \pi .
\end{gathered}
$$

The expression for the instantaneous current of the parallel switch is

$$
\begin{gathered}
i_{\mathrm{II}}=-\mathrm{QII}\left(i_{0(\omega)}+\sum_{n=1}^{\infty} i_{0 n}\right)=i_{\mathrm{II}(\omega)}+\sum_{n=1}^{\infty} i_{\mathrm{II} n}-\varrho \mathrm{QII} \sum_{n=1}^{\infty} i_{0 n}= \\
=-I_{m}[\alpha(1-\alpha / 2 \pi) \sin (\omega t-\varphi)] / 2 \pi+I_{m}(1-\alpha / 2 \pi) \sum_{n=1}^{\infty} \sin (n \alpha / 2) \times \\
\times[\sin ((n k+1) \omega t+n \alpha / 2-\varphi)-\sin ((n k-1) \omega t+n \alpha / 2+\varphi)] / n \pi+ \\
+I_{m} \frac{\alpha}{2 \pi} \sum_{n=1}^{\infty} \frac{\sin (n \alpha / 2)}{n \pi}\left[\frac{\sin \left((n k+1) \omega t+n \alpha / 2-\varphi_{(n k+1)}\right)}{\left(\cos ^{2} \varphi+(n k+1)^{2} \sin ^{2} \varphi\right)^{1 / \varepsilon}}-\right. \\
\left.-\frac{\sin ((n k-1) \omega t+n \alpha / 2-\varphi(n k-1))}{\left(\cos ^{2} \varphi+(n k-1)^{2} \sin ^{2} \varphi\right)^{1 / 6}}\right]+ \\
+I_{m} \sum_{m, n=1}^{\infty} \frac{\sin (m \alpha / 2) \sin (n \alpha / 2)}{m n \pi^{2}\left(\cos ^{2} \varphi+(m k+1)^{2} \sin ^{2} \varphi\right)^{1 / 2}} \times \\
\quad \times\{\sin [((m+n) k+1) \omega t+(m+n) \alpha / 2-\varphi((m+n) k+1)]+ \\
+\sin [((m-n) k+1) \omega t+(m-n) \alpha / 2-\varphi((m-n) k+1)]\}-
\end{gathered}
$$




$$
\begin{gathered}
+I_{m} \sum_{m, n=1}^{\infty} \frac{\sin (m \alpha / 2) \sin (n \alpha / 2)}{m n \pi^{2}\left(\cos ^{2} \varphi+(m k-1)^{2} \sin ^{2} \varphi\right)^{1 / 2}} \times \\
X\{\sin [((m+n) k-1) \omega t+(m+n) \alpha / 2-\varphi((m+n) k-1)]+ \\
+\sin [((m-n) k-1) \omega t+(m-n) \alpha / 2-\varphi((m-n) k-1)]\} .
\end{gathered}
$$

As it is seen from (1)-(3) the expressions for the instantaneous voltage and current of the series switch are analogous to (6), (7). From (7) one can see that the currents of the switches contain additional $((m+n) k+1)-$ th, $\quad((m+n) k-1)-$ th, $\quad((m-n) k+1)-$ th $\quad$ and $((m-n) k-1)$-th distortion harmonics. The regulator operation in the mode of $(n k+1)$-th and $(n k-1)$-th distortion harmonics being present in the load current serves as a reason for generating these additional distortion harmonics in the current of both switches.

\section{Frequency-power relationships}

On the basis of above formulae one can find the expressions for real powers in the load and in both switches. The real power in the load can be presented in the following form:

$$
\begin{gathered}
P_{0}=P_{0(\omega)}+\sum_{n=1}^{\infty} P_{0 n}=\left(U_{m} I_{m} / 2\right)\left\{(1-\alpha / 2 \pi)^{2}+\sum_{n=1}^{\infty}\left[\left(\sin ^{2}(n \alpha / 2)\right) / n^{2} \pi^{2}\right] \times\right. \\
\left.\quad \times\left[1 /\left(\cos ^{2} \varphi+(n k+1)^{2} \sin ^{2} \varphi\right)+1 /\left(\cos ^{2} \varphi+(n k-1)^{2} \sin ^{2} \varphi\right)\right]\right\} \cos \varphi,
\end{gathered}
$$

from which it can be seen that in the case under consideration the load consumes power at the fundamental and distortion harmonics. The distortion harmonics power is generated in the switches of the regulator. The formula for the real power in the series switch can be expressed in terms of

$$
P_{\mathrm{I}}=P_{\mathrm{I}(\omega)}+\sum_{n=1}^{\infty} P_{\mathrm{I} n}+P_{\mathrm{I}(\omega)}^{\prime}+\sum_{n=1}^{\infty} P_{\mathrm{I} n}^{\prime} .
$$

Note that $\left[{ }^{1}\right]$

$$
\begin{gathered}
P_{\mathrm{I}(\omega)}=\left(U_{m} I_{m} / 2\right)(\alpha / 2 \pi)^{2}(1-\alpha / 2 \pi) \cos \varphi \\
\sum_{n=1}^{\infty} P_{\mathrm{I} n}=-U_{m} I_{m}(1-\alpha / 2 \pi) \sum_{n=1}^{\infty}\left[\sin ^{2}(n \alpha / 2) \cos \varphi\right] / n^{2} \pi^{2}
\end{gathered}
$$

and $P_{\mathrm{I}(\omega)}=-\sum_{n=1}^{\infty} P_{\mathrm{I} n}$. Since $P_{\mathrm{I}}=0$, consequently $P_{\mathrm{I}(\omega)}^{\prime}=-\sum_{n=1}^{\infty} P_{\mathrm{I} n}^{\prime}$. The two last terms of the relationship (9) turn out to be of the form

$$
\begin{gathered}
P_{I(\omega)}^{\prime}=U_{m} I_{m}(\alpha / 2 \pi) \sum_{n=1}^{\infty}\left[\left(\sin ^{2}(n \alpha / 2) \cos \varphi / 2 n^{2} \pi^{2}\right] \times\right. \\
X\left[1 /\left(\cos ^{2} \varphi+(n k+1)^{2} \sin ^{2} \varphi\right)+1 /\left(\cos ^{2} \varphi+(n k-1)^{2} \sin ^{2} \varphi\right)\right], \\
\sum_{n=1}^{\infty} P_{I n}^{\prime}=-U_{m} I_{m}\left\{(1-\alpha / 2 \pi) \sum_{n=1}^{\infty}\left[\left(\sin ^{2}(n \alpha / 2)\right) / 2 n^{2} \pi^{2}\right] \times\right. \\
X\left[1 /\left(\cos ^{2} \varphi+(n k+1)^{2} \sin ^{2} \varphi\right)+1 /\left(\cos ^{2} \varphi+(n k-1)^{2} \sin ^{2} \varphi\right)\right]-
\end{gathered}
$$




$$
\begin{aligned}
& -\sum_{m, n=1}^{\infty}\left[(\sin (m \alpha / 2) \sin (n \alpha / 2) \sin ((m+n) \alpha / 2)) / m n(m+n) \pi^{3}\right] \times \\
& \times\left[1 /\left(\cos ^{2} \varphi+(n k+1)^{2} \sin ^{2} \varphi\right)+1 /\left(\cos ^{2} \varphi+(n k-1)^{2} \sin ^{2} \varphi\right)\right]-\quad(13) \\
& -\sum_{\substack{m, n=1 \\
m \neq n}}^{\infty}\left[(\sin (m \alpha / 2) \sin (n \alpha / 2) \sin ((m-n) \alpha / 2)) / m n(m-n) \pi^{3}\right] \times \\
& \left.\times\left[1 /\left(\cos ^{2} \varphi+(n k+1)^{2} \sin ^{2} \varphi\right)+1 /\left(\cos ^{2} \varphi+(n k-1)^{2} \sin ^{2} \varphi\right)\right]\right\} \cos \varphi= \\
& =\sum_{n=1}^{\infty}\left[1 /\left(\cos ^{2} \varphi+(n k+1)^{2} \sin ^{2} \varphi\right)+\right. \\
& \left.+1 /\left(\cos ^{2} \varphi+(n k-1)^{2} \sin ^{2} \varphi\right)\right]\left(P_{\text {In }} / 2\right)+P_{m, n}^{\prime} .
\end{aligned}
$$

The expression for the real power of the parallel switch

$$
P_{\mathrm{II}}=P_{\Pi(\omega)}+\sum_{n=1}^{\infty} P_{\mathrm{II} n}+P_{\mathrm{II}(\omega)}^{\prime}+\sum_{n=1}^{\infty} P_{\mathrm{II} n}^{\prime}
$$

is analogous to (9). It is known $\left.{ }^{1}\right]$ that $P_{\mathrm{II}(\omega)}=-P_{\mathrm{I}(\omega)}$ and $\sum_{n=1}^{\infty} P_{\mathrm{I} n}=$ $=-\sum_{n=1}^{\infty} P_{\amalg n}$. The other terms of (14) are found to be

$$
\begin{gathered}
P_{\mathrm{II}(\omega)}^{\prime}=[(1-\alpha / 2 \pi) 2 \pi / \alpha] P_{\mathrm{I}(\omega),}^{\prime} \\
\sum_{n=1}^{\infty} P_{\mathrm{IIn} n}^{\prime}=[\alpha / 2(2 \pi-\alpha)] \sum_{n=1}^{\infty}\left[1 /\left(\cos ^{2} \varphi+(n k+1)^{2} \sin ^{2} \varphi\right)+\right. \\
\left.+1 /\left(\cos ^{2} \varphi+(n k-1)^{2} \sin ^{2} \varphi\right)\right] P_{\mathrm{I} n}-P_{m, n}^{\prime} .
\end{gathered}
$$

Since [ $\left.{ }^{1}\right] P_{\mathrm{II}}=0$ and $P_{\mathrm{II}(\omega)}=-\sum_{n=1}^{\infty} P_{\mathrm{II} n}$, consequently $P_{\mathrm{II}(\omega)}^{\prime}=-\sum_{n=1}^{\infty} P_{I I I n}^{\prime}$.

From the relationships (8), (13), (16) one can see that power consumption at distortion harmonics in the load is

$$
\sum_{n=1}^{\infty} P_{0 n}=-\left(\sum_{n=1}^{\infty} P^{\prime}{ }_{I n}+\sum_{n=1}^{\infty} P^{\prime}{ }_{I I n}\right) \text {. }
$$

The power generated at the additional distortion harmonics in the parallel switch $\left(-P_{m, n}^{\prime}\right)$, is consumed in the series switch.

Comparing the two modes of regulator operation in the case of distortion harmonics being present in the load current (mode II), more power is both consumed at the fundamental harmonic and generated at distortion harmonics in the series switch. In the parallel switch less power is both consumed at distortion harmonics and generated at the fundamental harmonic.

Note that if $z=R$, then $i_{\mathrm{I}}=i_{z}, i_{\mathrm{II}}=0$. Consequently,

$$
P_{I I(\omega)}=-P_{I I(\omega)}^{\prime}=-\sum_{n=1}^{\infty} P_{I I n}=\sum_{n=1}^{\infty} P_{I I n}^{\prime},
$$

and therefore in the process of energy exchange in the circuit only the series switch participates.

In order to illustrate the foregoing power formulae obtained in this discussion, one can find their per unit values for the case $z=R, \alpha=\pi$, assuming that the unit power is equal to $U_{m} I_{m} / 2$. 
Then

$$
\begin{aligned}
& P_{\mathrm{I}(\omega)}^{*}=2 P_{\mathrm{I}(\omega)} / U_{m} I_{m}=-P_{\Pi(\omega)}^{\prime *}=1 / 8, \\
& \sum_{n=1}^{\infty} P_{\mathrm{I} n}^{*}=-\sum_{n=1}^{\infty} P_{\Pi n}^{*}=-\frac{1}{\pi^{2}}\left(1+\frac{1}{3^{2}}+\ldots+\frac{1}{(2 n+1)^{2}}+\ldots\right)=-\frac{1}{8}, \\
& P_{\mathrm{I}(\omega)}^{\prime *}=-\sum_{n=1}^{\infty} P_{\mathrm{In}}^{\prime *}=1 / 8 \\
& P_{\mathrm{II}(\omega)}^{\prime *}=-\sum_{n=1}^{\infty} P_{\Pi n}^{\prime *}=1 / 8 \\
& P_{0(\omega)}^{*}=\sum_{n=1}^{\infty} P_{0 n}^{*}=1 / 4 .
\end{aligned}
$$

When $k \omega \gg \omega$, in the case of an inductive or $(L+R)$ load the regulator under consideration operates in mode I (same as a regulator regarded in the first part of the paper).

\section{Conclusions}

Frequency-power relationships have been derived for an ideal alternating voltage switching regulator operating in mode II (distortion harmonics being present in the load current). From these relationships it can be seen that power consumption at distortion harmonics in the load is satisfied by power generation at the same harmonics in the switches.

Comparing the two modes of regulator operation, in the case of mode II more power is both consumed at the fundamental harmonic and generated at distortion harmonics in the series switch. In the parallel switch less power is both consumed at distortion harmonics and generated at the fundamental harmonic.

The regulator operation in mode II is the reason for additional distortion harmonics being generated in the current of both switches. The power generated at these harmonics in the parallel switch, is consumed in the series switch.

\section{REFERENCES}

1. О я в е эр М., С а р в В., Изв. АН ЭССР, Физ. Матем., 28, № 1, 48-53 (1979).

2. Ж а р к и й Б. К., Го л у бе в В. В., Препринт-96 ИЭД АН УССР, Киев, 1975.

Academy of Sciences of the Estonian SSR, Institute of Thermophysics and Electrophysics 
Maire OJAVEER

\section{HARMOONILISTEVAHELINE ENERGIAVAHETUS \\ VAHELDUVPINGEREGULAATORI LULITITES KORGSAGEDUSLIKU \\ LAIUS-IMPULSSMODULATSIOONI KORRAL. II}

Artiklis on analüüsitud sagedus-energeetilisi seoseid vahelduvpingeregulaatoris, mille koormusvool sisaldab moonutusharmoonilisi. Nimetatud seostest nähtub, et koormus tarbib nii põhiharmoonilise kui ka moonutusharmooniliste võimsust; viimane genereeritakse regulaatori lülitites.

\section{Maüpe ОЯВЕЭР}

\section{ОБМЕН ЭНЕРГИИ МЕЖДУ ГАРМОНИКАМИ \\ В КЛЮЧАХ РЕГУЛЯТОРА ПЕРЕМЕННОГО НАПРЯЖЕНИЯ ПРИ ВЫСОКОЧАСТОТНОЙ ШИРОТНО-ИМПУЛЬСНОИ МОДУЛЯЦИИ. II}

Проведен анализ основных частотно-энергетических соотношений в ключевом регуляторе переменного напряжения при наличии искажающих гармоник в токе нагрузки. Установлено, что нагрузка потребляет энергию как основной, так и искажающих гармоник. Последние генерируются в ключах регулятора. 